\title{
(C) OPEN ACCESS \\ Interstitial lung abnormalities: erecting fences in the path towards advanced pulmonary fibrosis
}

\author{
Gary M Hunninghake
}

Correspondence to

Dr Gary M Hunninghake,

Pulmonary and Critical Care Division, Department of Medicine, Brigham and Women's Hospital, Boston, MA 02115, USA;

ghunninghake@bwh.harvard. edu

Received 5 November 2018 Revised 21 November 2018 Accepted 3 December 2018 Published Online First 5 February 2019

\begin{abstract}
Interstitial lung abnormalities, when present in members of undiagnosed family members recruited on the basis of familial interstitial pneumonia, or in undiagnosed research participants, have been associated with a syndrome that includes distinct sets of imaging abnormalities, restrictive physiological and exercise impairments, and an increased prevalence of histopathological findings, and genetic predictors, that have been noted in patients with idiopathic pulmonary fibrosis. Recent longitudinal studies have demonstrated that qualitative and quantitative assessments of interstitial abnormalities are associated with accelerated lung function decline, an increased rate of clinical diagnoses of interstitial lung disease and an increased rate of mortality. In this perspective, in addition to reviewing the prior information, four major efforts that could help the field of early pulmonary fibrosis detection move forward are discussed. These efforts include: (1) developing standards for characterising and reporting imaging findings from patients with existing CTs; (2) developing consensus statements on when undiagnosed and asymptomatic imaging abnormalities should be considered a disease; (3) identifying populations for which screening efforts might be beneficial; and (4) considering approaches to developing effective secondary prevention trials.
\end{abstract}

\section{INTRODUCTION}

If people are falling over the edge of a cliff and sustaining injuries, the problem could be dealt with by stationing ambulances at the bottom or erecting a fence at the top. Unfortunately, we put far too much effort into the provision of ambulances and far too little into the simple approach of erecting fences. Denis Burkitt, in a paraphrase ${ }^{1}$ of the ideas in a poem 'The Ambulance Down in the Valley' (1895) by Joseph Malins

While Denis Burkitt, an Irish paediatric surgeon, is best known for his description of, and work to cure, a common childhood cancer which now bears his name (Burkitt's lymphoma), he is also remembered for his efforts to increase the emphasis on prevention in medicine. This quotation, which alludes to his frustration at the low priority preventive efforts for common malignancies were given in medical education, ${ }^{2}$ is also an apt description of the current focus of medical care in pulmonary fibrosis. To be fair, the process of erecting effective fences in the path to advanced pulmonary fibrosis will not be simple and will require more investigation and thoughtful planning.
How can we begin the process of stopping, or slowing, our patient's progress towards the cliff whose precipice often begins with the development of respiratory symptoms? The answer to this question is not entirely straightforward; however, a rational approach is beginning to take shape. To explore this topic, let us confront the controversial issues in the field of early pulmonary fibrosis detection and consider approaches that may help address the most important challenges.

In this perspective I will briefly discuss background information with an emphasis on discussing longitudinal outcome data, much of which have been published since prior reviews. Given the scope of the problem of undiagnosed early stages of pulmonary fibrosis I will discuss a logical set of approaches that begin to address those with existing chest CTs, groups where research on further screening may be warranted and future secondary prevention trials.

\section{BACKGROUND}

While the concept of early disease detection in those at risk for pulmonary fibrosis is not new, ${ }^{3}$ accelerating interest in this topic likely stems from clinical trial results demonstrating that the rate of decline in pulmonary function in patients with idiopathic pulmonary fibrosis (IPF), the most severe form of pulmonary fibrosis, ${ }^{4}$ can be slowed with antifibrotic medical therapy, ${ }^{56}$ even when started in patients with less severe disease. ${ }^{78}$ If durable benefits like these extend to those in the earliest stages of their disease process it is rational to conclude that major reductions in the morbidity and mortality associated with a delay in the development of more advanced stages of pulmonary fibrosis are achievable.

What defines an early stage of pulmonary fibrosis? We don't have answer to this question yet. However, replicable findings are accumulating that should be helpful in providing a core body of evidence on which consensus definitions could be based. Much of the recent evidence emanates from a starting point that begins with chest CT assessments of undiagnosed family members of patients with Familial Interstitial Pneumonia (FIP) ${ }^{9-11}$ and undiagnosed participants in epidemiological studies initiated to address other medical concerns. ${ }^{12-14}$

Although the definition varies slightly by study, a common definition of FIP includes the presence of more than one first-degree relative in a family with a diagnosis of an idiopathic interstitial pneumonia. ${ }^{15}$ Standardised methods of declaring early pulmonary fibrosis in undiagnosed relatives of patients with FIP (or determining that FIP is present an additional family member who has not been clinically diagnosed) have not been clearly
To cite: Hunninghake GM. Thorax 2019:74:506-511. 
defined. In undiagnosed research participants, the term interstitial lung abnormalities (ILA) is often used to characterise the chest CT scan image when abnormalities are present that are similar to those noted in patients with an interstitial lung disease (ILD). ${ }^{13141617}$ In some studies, the research participant with an abnormal chest CT is referred to as having subclinical ILD. ${ }^{18-20}$ Definitions for ILA and subclinical ILD (also referred to by other names including 'dirty-lung, ${ }^{21}$ or preclinical ILD) ${ }^{22}$ vary more widely by study. Definitions for ILA include qualitative assessments of individual chest CTs in studies with unique recruitment criteria by single $e^{23}$ or multiple ${ }^{24}$ imaging readers with differing imaging characterisation criteria. ${ }^{1316} 1823$ Definitions of quantitative assessments of interstitial features include those that result from densitometric ${ }^{12}$ and algorithmically trained local histogram measures. ${ }^{25}$ Quantitative metrics of interstitial abnormalities have been termed high attenuation areas when referring to densitometric assessments, ${ }^{12}$ and interstitial features when referring to local histogram measures. ${ }^{25}$ Standardised methods of declaring early pulmonary fibrosis in an undiagnosed research participant have also not been clearly defined. Some effort to develop these standards among the various research groups should be undertaken so that readers can adequately compare findings across populations.

\section{LONGITUDINAL OUTCOMES AND ILA}

Prior reviews ${ }^{26-28}$ have covered some of the evidence that demonstrates common imaging, physiological and genetic links between research participants with ILA, or subclinical ILD, and patients with a known diagnosis of ILD, or IPF. This information will not be represented here in detail. Briefly, insights from this work include the fact that although ILA is more prevalent $(2 \%-10 \%$ in adults $)^{12} 1316$ than IPF is reported to be $(\sim 0.5 \%$ of the population >age 65), ${ }^{29-31}$ research participants with ILA can have a similar syndrome that includes overlapping imaging findings, ${ }^{32}$ restrictive physiological and exercise impairments, ${ }^{13} 1433-35$ and an increased prevalence of histopathological findings, ${ }^{96}$ genetic predictors ${ }^{9143237}$ and profibrotic biomarkers, ${ }^{1938}{ }^{39}$ which have been noted in patients with IPF.

Although this information is compelling and suggests important connections between undiagnosed research participants with ILA and patients with clinically identified pulmonary fibrosis, the argument to pursue clinical screening efforts would be much less convincing if evidence did not suggest that those with ILA could progress and experience adverse longitudinal outcomes. This has not been the case. As reviewed in table 1, numerous groups have demonstrated data on the rates of imaging progression ${ }^{16} 18234041$

Table 1 Comparisons of longitudinal outcome measures in research participants with interstitial lung abnormalities (ILA) or subclinical interstitial lung disease (ILD) by cohort

\begin{tabular}{|c|c|c|c|c|c|c|c|c|c|}
\hline \multirow[b]{2}{*}{ Variable } & \multicolumn{9}{|c|}{ Per cent or median/means where appropriate and noted } \\
\hline & MESAT & Nagano, Japan $\ddagger$ & COPDGene§ & MILDף & $\mathrm{FHS}^{* *}$ & ECLIPSE†† & NLST‡¥ & $\begin{array}{l}\text { AGES- } \\
\text { Reykjavik§§ }\end{array}$ & BWH RoCInף \\
\hline Baseline prevalence of ILA (\%) & 11 & 3 & 8 & 4 & 7 & 9 & 10 & 7 & 8 \\
\hline \multicolumn{10}{|l|}{ Radiological progression } \\
\hline $\begin{array}{l}\text { Overall progression, follow-up } \\
\text { time }\end{array}$ & - & $\begin{array}{l}46 \% \\
4 \text { years }\end{array}$ & - & $\begin{array}{l}25 \% \\
3 \text { years }\end{array}$ & $\begin{array}{l}43 \% \\
6 \text { years }\end{array}$ & - & $\begin{array}{l}20 \% \\
2 \text { years }\end{array}$ & - & - \\
\hline \multicolumn{10}{|l|}{ Morbidity } \\
\hline $\begin{array}{l}\text { FVC annual rate of decline } \\
\text { (compared with general pop) }\end{array}$ & - & - & - & - & $\begin{array}{l}\sim 2 \text { times greater } \\
\text { (for those } \\
\text { with imaging } \\
\text { progression) }\end{array}$ & - & - & - & - \\
\hline Development of ARDS & - & - & - & - & - & - & - & - & $\begin{array}{l}\text { OR } 4.2 \text { (among } \\
\text { those presenting } \\
\text { to the ICU with } \\
\text { SIRS or sepsis) }\end{array}$ \\
\hline $\begin{array}{l}\text { Development of clinical ILD/PF } \\
\text { diagnoses }\end{array}$ & $\begin{array}{l}\text { Increased ILD } \\
\text { diagnoses in } \\
\text { those with } \\
\text { elevated } \\
\text { measures of } \\
\text { HAA }\end{array}$ & - & - & - & - & - & $\begin{array}{l}\text { Some cases } \\
\text { identified on death } \\
\text { certificates }\end{array}$ & $\begin{array}{l}\text { Some cases } \\
\text { identified on death } \\
\text { certificates }\end{array}$ & $\begin{array}{l}\text { Some cases } \\
\text { identified on } \\
\text { autopsy }\end{array}$ \\
\hline \multicolumn{10}{|l|}{ Mortality } \\
\hline Risk of death & $\begin{array}{l}\text { Increased } \\
\text { mortality in those } \\
\text { with elevated } \\
\text { measures of HAA }\end{array}$ & - & $\begin{array}{l}\text { RR } 1.6^{*} \\
\text { (also increased } \\
\text { in those with } \\
\text { increased } \\
\text { quantitative } \\
\text { interstitial } \\
\text { changes) }\end{array}$ & - & $\operatorname{RR} 2.2^{*}$ & RR $1.4^{*}$ & $\mathrm{RR}>4.0^{*}$ & RR 1.3 & RR 2.1 \\
\hline Absolute mortality & - & - & $\begin{array}{l}10 \% \\
\sim 5 \text { years }\end{array}$ & - & $\begin{array}{l}7 \% \\
\sim 4 \text { years }\end{array}$ & $\begin{array}{l}11 \% \\
\sim 3 \text { years }\end{array}$ & $\begin{array}{l}97 \% \\
\sim 12 \text { years }\end{array}$ & $\begin{array}{l}56 \% \\
\sim 9 \text { years }\end{array}$ & $\begin{array}{l}37 \% \\
\sim 28 \text { days }\end{array}$ \\
\hline \multicolumn{10}{|c|}{ 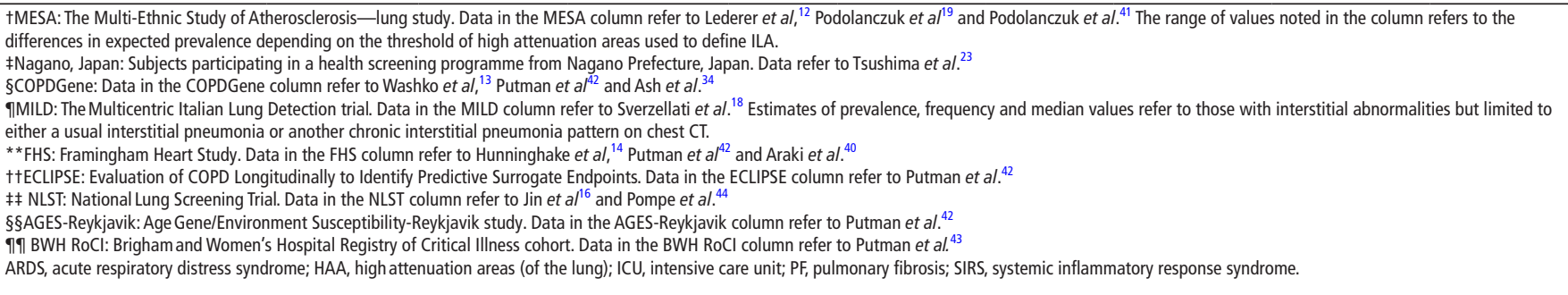 } \\
\hline
\end{tabular}



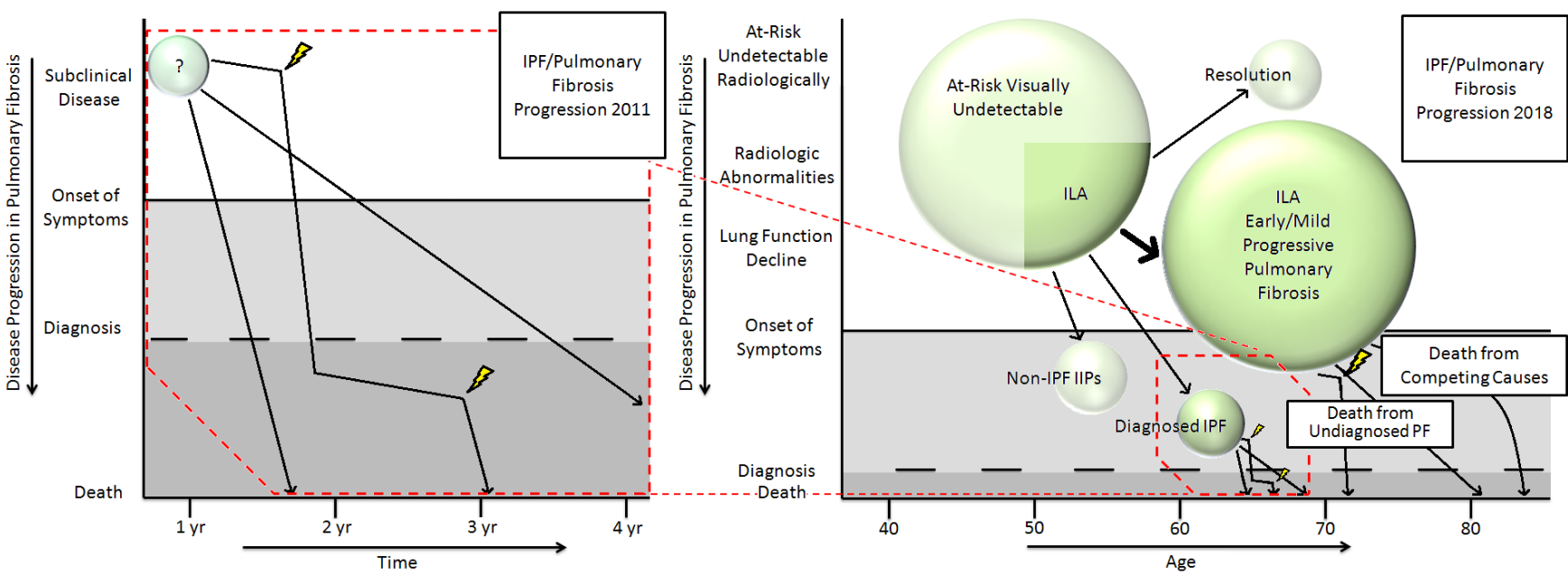

Figure 1 The figure (adapted from Ley et al (2011) $\left.{ }^{56}\right]$ ) includes a speculative representation of how idiopathic pulmonary fibrosis (IPF) progression might occur from those with an early stage of pulmonary fibrosis (PF) or subclinical disease (left panel). An updated and expanded representation of current knowledge (right panel) which highlights the under-recognised burden of early PF, the risk for accelerated lung function decline and early death ${ }^{40} 42$ even among those not diagnosed with IPF. IIP, idiopathic interstitial pneumonia; ILA, interstitial lung abnormalities.

(including an interval development of fibrosis in general, and imaging patterns consistent with usual interstitial pneumonia (UIP) in particular) ${ }^{40} 41$ experienced by research participants with ILA. Additionally, while ILA progression has been associated with an accelerated lung function decline and an increased rate of mortality, ${ }^{40}$ ILA in general (as well as quantitative metrics suggestive of ILA) have been associated with increased rates of clinical ILD/pulmonary fibrosis development, ${ }^{41-43}$ and an increased risk for death (including elevated respiratory-related mortality rates from pulmonary fibrosis and acute respiratory distress syndrome). ${ }^{19}{ }^{34} 42-45$ In total these findings suggest a paradigm shift in our thinking about the early undiagnosed phase of pulmonary fibrosis is warranted (see figure 1).

These consistent and replicable findings show us that the development of fibrotic imaging findings and accelerated lung function decline frequently occur before the development of respiratory symptoms leads to a diagnosis of clinical ILD. While there is no current evidence that early interventions will lead to improved outcomes in those with ILA the case for indifference is becoming harder to support. In the remainder of this perspective I will discuss steps that should help lay the foundation on which fences attempting to obstruct the path towards advanced pulmonary fibrosis could be built (summarised in table 2).

\section{STANDARDISING RADIOLOGICAL REPORTING OF ILA}

The first step in this process includes developing a consensus on reporting ILA in patients with existing chest CTs obtained when an underlying clinical ILD, or early stage of pulmonary fibrosis, was not initially suspected. Much has been written on

Table 2 Key findings in interstitial lung abnormalities, important missing information and action items

\begin{tabular}{|c|c|c|c|}
\hline Key findings & Goal & Missing information & Action items \\
\hline $\begin{array}{l}\text { Interstitial lung abnormalities (a diverse set } \\
\text { of chest CT imaging findings suggestive of } \\
\text { an underlying interstitial lung disease) are } \\
\text { relatively common in older adults and are } \\
\text { associated with adverse outcomes. }\end{array}$ & $\begin{array}{l}\text { To develop radiological standards on } \\
\text { reporting interstitial abnormalities. }\end{array}$ & $\begin{array}{l}\text { Do specific imaging findings help predict } \\
\text { progression and adverse outcomes in those } \\
\text { with interstitial abnormalities? }\end{array}$ & $\begin{array}{l}\text { Studies should focus on trying to identify if } \\
\text { specific radiological features and patterns } \\
\text { help predict adverse outcomes in those with } \\
\text { interstitial abnormalities. }\end{array}$ \\
\hline $\begin{array}{l}\text { Studies of physiological and } \\
\text { histopathological data suggest that some } \\
\text { people with interstitial abnormalities have } \\
\text { an early stage of pulmonary fibrosis. }\end{array}$ & $\begin{array}{l}\text { To develop consensus statements } \\
\text { on when an imaging abnormality } \\
\text { constitutes a disease in an undiagnosed } \\
\text { and asymptomatic person. }\end{array}$ & $\begin{array}{l}\text { Can consensus on updated disease } \\
\text { definitions be achieved? }\end{array}$ & $\begin{array}{l}\text { Committees should be developed so that } \\
\text { evidence-based consensus guidelines and } \\
\text { position statements from major societies } \\
\text { could be generated and updated when } \\
\text { appropriate. }\end{array}$ \\
\hline $\begin{array}{l}\text { Some groups appear to be at an increased } \\
\text { risk to develop interstitial abnormalities. }\end{array}$ & $\begin{array}{l}\text { To develop effective screening } \\
\text { programmes in high-risk groups. }\end{array}$ & $\begin{array}{l}\text { What are the results of early pulmonary } \\
\text { fibrosis screening studies? What groups are } \\
\text { interested in participating in these types of } \\
\text { studies? }\end{array}$ & $\begin{array}{l}\text { In addition to encouraging publication } \\
\text { from studies actively participating in } \\
\text { screening efforts, funding agencies should } \\
\text { consider encouraging these efforts so that } \\
\text { populations for secondary prevention trials } \\
\text { can be developed. }\end{array}$ \\
\hline $\begin{array}{l}\text { Antifibrotic therapy slows lung function } \\
\text { decline in patients with IPF, even among } \\
\text { those more preserved measures of } \\
\text { pulmonary function. }\end{array}$ & $\begin{array}{l}\text { To conduct secondary prevention trials in } \\
\text { patients with early stages of pulmonary } \\
\text { fibrosis. }\end{array}$ & $\begin{array}{l}\text { What groups with interstitial abnormalities } \\
\text { would benefit the most from early } \\
\text { therapeutic intervention? Are there } \\
\text { secondary endpoints that help predict longer } \\
\text { term outcomes in those with interstitial } \\
\text { abnormalities? }\end{array}$ & $\begin{array}{l}\text { Early discussions should be undertaken } \\
\text { to consider how to define reasonable } \\
\text { endpoints and how to appropriately } \\
\text { power trials in those with early stages of } \\
\text { pulmonary fibrosis. }\end{array}$ \\
\hline
\end{tabular}


methods for reporting imaging patterns, ${ }^{46}$ and the importance of, ${ }^{47}$ a chest CT in the evaluation of a patient suspected of having IPF. Efforts have also been made to standardise the reporting of imaging features found in patients suspected to have an ILD in general. ${ }^{48}$ Despite this body of work, our findings demonstrate that radiological reports of these imaging features and patterns can be quite variable in the clinical setting when the chest CT scan is performed for another reason. ${ }^{36439}$ For example, when an oncologist orders a chest CT scan to exclude recurrent malignancy and the radiologist's report of interstitial features is limited to the statement 'bilateral subpleural reticulation is present' it could be argued that this report does not seem designed to raise an appropriate level of clinical concern. ${ }^{364349}$ As a contrast, the radiologist's report could include the statement, 'Bilateral subpleural reticulation is present. These findings may represent an early stage of an ILD or pulmonary fibrosis. In the right clinical context, a referral to a pulmonologist for further evaluation is recommended.'

As first suggested by Wells and Kokosi, ${ }^{49}$ a consensus position paper on recommendations for radiological reporting of ILA, and ILA subgroups, similar to those that exist for patients with clinically suspected IPF, ${ }^{46}$ is warranted. However, for standardised radiological reporting of ILA to be effective, it would be important to determine if different imaging features and patterns of ILA confer variable outcomes. Based on the diversity of ILA phenotypes $^{32}$ and ILDs in general, ${ }^{50}$ current definitions of ILA ${ }^{24}$ almost certainly include a spectrum of diverse forms of ILD (as well as some cases of other conditions masquerading as ILD). While there are data to suggest that different imaging patterns in undiagnosed research participants with ILA are associated with different degrees of relative lung volume reduction ${ }^{13}$ and exercise limitation, ${ }^{51}$ it will be critical to determine if different imaging features and patterns (or the quantity of these imaging features and patterns) confer variable longitudinal outcomes. For example, it would be helpful to determine if the increased rate of mortality noted in research participants with ILA is different in those whose ILA is defined by the presence of centrilobular ground glass nodules versus those whose ILA is defined by the presence of traction bronchiectasis. These imaging findings are often present in distinct forms of ILD and are felt to confer different prognoses when identified in the clinical setting. ${ }^{52}$ Attempts should be also made to develop consensus recommendations on further evaluation and clinical referral.

\section{FROM ABNORMALITY TO DISEASE}

If agreement can be reached on standardised methods of reporting chest CT imaging in the clinical setting, we should be prepared to address the question of what set of findings constitutes merely an imaging abnormality and what set of findings constitutes a disease. To what extent should reduced, or declining, lung volume or gas exchange measures be included in these definitions? When should a lung biopsy be recommended for a diagnosis to be made? Should we consider separating some diseases into clinical stages (eg, would there be a value to defining an early and/or mild stage of IPF)? These distinctions are important for multiple reasons.

The most recent guidelines from the American Thoracic, European Respiratory, and Japanese Respiratory Societies, and Latin American Thoracic Association, on IPF diagnosis provide guidelines on the diagnostic criteria in symptomatic, and asymptomatic, patients suspected of having clinical IPF. ${ }^{53}$ We may be able to agree as an ILD community that a chest CT demonstrating a UIP pattern, even in an asymptomatic older patient (without clinical or serological evidence for an alternate diagnosis), can be sufficient to diagnose IPF as a disease. The label 'disease' is important as this would qualify the patient for antifibrotic ${ }^{5} 6$ therapy. However, given the relatively high prevalence of ILA in the general population ${ }^{14}$ (much of which could be described as having an indeterminate for UIP pattern ${ }^{32} 53$ ) it is easy to see how these guidelines could lead to overdiagnosis of 'disease' and the institution of medical therapy in groups who would not have made entry criteria into the studies of antifibrotic therapy. ${ }^{56}$ If we do use the term 'disease' perhaps creating clinical subsets (eg, early and/or mild IPF) would allow us to define subgroups for whom we should acknowledge that the benefit of medical therapy is currently less clear.

\section{IDENTIFYING POPULATIONS FOR SCREENING}

Although general chest CT screening efforts for pulmonary fibrosis are not warranted due to small, but measurable, increases in the rate of malignancy that are conferred by accumulating radiation exposure, ${ }^{54}$ there are groups at a higher risk for subclinical ILD for whom the benefits of screening may one day be realised. Given the potential scope of the problem, groups have become interested in, and the National Institutes of Health (NIH) is funding, screening efforts in undiagnosed patients with rheumatoid arthritis (NIH grant numbers K23HL119558 and K23HL138131) and in undiagnosed first-degree relatives of patients with FIP specifically (NIH grant numbers P01HL092870) and with an idiopathic interstitial pneumonia with pulmonary fibrosis more generally (NIH grant numbers R01HL130974 and R01HL103676). There may be other groups for whom screening efforts might be of value. In addition to discovering shared and novel pathophysiological mechanisms, ${ }^{9}$ hopefully these studies will also address other important questions. Are there important, and easily measured, factors (beyond chest CT imaging) that help predict underlying pulmonary fibrosis in populations screened? How commonly do those screened for an early and/or mild stage of pulmonary fibrosis progress (and over what period of time)? How do individuals respond to receiving information about the presence of an early and/or mild stage of pulmonary fibrosis? What are the perceived benefits and negative consequences of receiving this type of information? These questions are critical to address before investments in prevention, and clinical trials, in screened populations are considered.

\section{PREVENTION, CLINICAL TRIALS AND PRIMARY OUTCOMES}

While the ultimate goal of this work is to consider if interventions targeted to those with early and/or mild stages of pulmonary fibrosis would mitigate or prevent the progression to more advanced stages of disease, this topic should be approached with some caution. It is not known what percentage of people diagnosed with an early and/or mild stage of pulmonary fibrosis would want to participate in an interventional study. Interventional studies should consider the possibility that primary preventive efforts (eg, smoking cessation) could be of value. The tolerance of drug side effects is likely to be much lower in asymptomatic people who may need to be on therapy for longer periods of time. Interventional studies hoping to achieve more global patient-oriented benefits should carefully consider other competing risks such as lung function decline from COPD or mortality from coronary artery disease (particularly in older populations). Although imaging progression of ILA has been associated with an accelerated decline in measures of $\mathrm{FVC},{ }^{40}$ the annual rates of FVC decline in those with ILA are substantially less than 
the declines noted in clinical studies of patients with IPF. $^{55}$ This suggests that future clinical trials of those with early and/or mild stages of pulmonary fibrosis may need to enroll larger numbers, follow patients for longer periods of time, or consider alternate surrogate enpoints. In addition, some effort should be given to enriching trials with those experiencing greater degrees of physiologic decline so that they can be sufficiently powered to detect important differences.

\section{SUMMARY AND FUTURE DIRECTIONS}

As the process of early disease detection for pulmonary fibrosis moves closer to becoming a reality it is important to stop to review the information that has led to this point. In this perspective, I reviewed the background and longitudinal outcome data that suggest the scope of the problem of early and/or mild pulmonary fibrosis. Deficiencies in our knowledge in this field were highlighted. In order to make progress to mitigate, or prevent, the advancement towards pulmonary fibrosis a set of steps was described. These steps include standardising chest CT image reporting and considering the role redefining disease definitions. Current efforts and goals of screening efforts for pulmonary fibrosis in unique populations were described. This perspective concludes with some thoughts on what issues might be important to address before future interventional trials are considered.

Hopefully we will continue to make progress, and continue to invest in, the processes of erecting effective fences that may one day help keep more people included on the grassy fields of good health. Walls to exclude people are rarely effective.

Contributors GMH was the sole author of this publication.

Funding GMH is supported by NIH grants: R01 HL111024, R01 HL135142 and R01 HL130974.

Competing interests GMH has been receiving funding from the National Institutes of Health and has performed consulting for the Gerson Lehrman Group, Medna, Genentech, Boehringer-Ingelheim and Mitsubishi Chemical.

Patient consent for publication Not required.

Provenance and peer review Commissioned; externally peer reviewed.

Open access This is an open access article distributed in accordance with the Creative Commons Attribution Non Commercial (CC BY-NC 4.0) license, which permits others to distribute, remix, adapt, build upon this work non-commercially, and license their derivative works on different terms, provided the original work is properly cited, appropriate credit is given, any changes made indicated, and the use is non-commercial. See: http://creativecommons.org/licenses/by-nc/4.0/.

\section{REFERENCES}

1 Burkitt D. An approach to the reduction of the most common Western cancers. The failure of therapy to reduce disease. Arch Surg 1991;126:345-7.

2 Coakley D. Denis Burkitt and his contribution to haematology/oncology. Br J Haematol 2006:135:17-25.

3 Bitterman PB, Rennard SI, Keogh BA, et al. Familial idiopathic pulmonary fibrosis. Evidence of lung inflammation in unaffected family members. N Eng/ J Med 1986:314:1343-7.

4 American Thoracic Society/European Respiratory Society International Multidisciplinary Consensus Classification of the Idiopathic Interstitial Pneumonias. This joint statement of the American Thoracic Society (ATS), and the European Respiratory Society (ERS) was adopted by the ATS board of directors, June 2001 and by the ERS Executive Committee, June 2001. Am J Respir Crit Care Med 2002;165:277-304.

5 Richeldi L, du Bois RM, Raghu G, et al. Efficacy and safety of nintedanib in idiopathic pulmonary fibrosis. N Engl J Med 2014;370:2071-82.

6 King TE, Bradford WZ, Castro-Bernardini S, et al. A phase 3 trial of pirfenidone in patients with idiopathic pulmonary fibrosis. N Eng/ J Med 2014;370:2083-92.

7 Taguchi Y, Ebina M, Hashimoto S, et al. Efficacy of pirfenidone and disease severity of idiopathic pulmonary fibrosis: Extended analysis of phase III trial in Japan. Respir Investig 2015;53:279-87.

8 Kolb M, Richeldi L, Behr J, et al. Nintedanib in patients with idiopathic pulmonary fibrosis and preserved lung volume. Thorax 2017;72:340-6.
9 Kropski JA, Pritchett JM, Zoz DF, et al. Extensive phenotyping of individuals at risk for familial interstitial pneumonia reveals clues to the pathogenesis of interstitial lung disease. Am J Respir Crit Care Med 2015;191:417-26.

10 Steele MP, Speer MC, Loyd JE, et al. Clinical and pathologic features of familial interstitial pneumonia. Am J Respir Crit Care Med 2005;172:1146-52.

11 Rosas IO, Ren P, Avila NA, et al. Early interstitial lung disease in familial pulmonary fibrosis. Am J Respir Crit Care Med 2007;176:698-705.

12 Lederer DJ, Enright PL, Kawut SM, et al. Cigarette smoking is associated with subclinical parenchymal lung disease: the Multi-Ethnic Study of Atherosclerosis (MESA)-lung study. Am J Respir Crit Care Med 2009;180:407-14.

13 Washko GR, Hunninghake GM, Fernandez IE, et al. Lung volumes and emphysema in smokers with interstitial lung abnormalities. N Engl J Med 2011;364:897-906.

14 Hunninghake GM, Hatabu H, Okajima Y, et al. MUC5B promoter polymorphism and interstitial lung abnormalities. N Engl J Med 2013;368:2192-200.

15 Talbert JL, Schwartz DA, Pulmonary Fibrosis F. In: Adam MP, Ardinger HH, Pagon RA, et al., eds. GeneReviews((R)). Seattle 1993.

16 Jin GY, Lynch D, Chawla A, et al. Interstitial lung abnormalities in a CT lung cancer screening population: prevalence and progression rate. Radiology 2013:268:563-71.

17 Axelsson GT, Putman RK, Araki T, et al. Interstitial lung abnormalities and self-reported health and functional status. Thorax 2018;73:884-6.

18 Sverzellati N, Guerci L, Randi G, et al. Interstitial lung diseases in a lung cancer screening trial. Eur Respir J 2011;38:392-400.

19 Podolanczuk AJ, Oelsner EC, Barr RG, et al. High attenuation areas on chest computed tomography in community-dwelling adults: the MESA study. Eur Respir J 2016:48:1442-52.

20 Sack C, Vedal S, Sheppard L, et al. Air pollution and subclinical interstitial lung disease: the Multi-Ethnic Study of Atherosclerosis (MESA) air-lung study. Eur Respir J 2017; 50:1700559.

21 Gückel C, Hansell DM. Imaging the 'dirty lung'--has high resolution computed tomography cleared the smoke? Clin Radiol 1998;53:717-22.

22 Gochuico BR, Avila NA, Chow CK, et al. Progressive preclinical interstitial lung disease in rheumatoid arthritis. Arch Intern Med 2008;168:159-66.

23 Tsushima K, Sone S, Yoshikawa S, et al. The radiological patterns of interstitial change at an early phase: over a 4-year follow-up. Respir Med 2010;104:1712-21.

24 Washko GR, Lynch DA, Matsuoka S, et al. Identification of early interstitial lung disease in smokers from the COPDGene Study. Acad Radiol 2010;17:48-53.

25 Ash SY, Harmouche R, Ross JC, et al. The objective identification and quantification of interstitial lung abnormalities in smokers. Acad Radiol 2017:24:941-6.

26 Doyle TJ, Hunninghake GM, Rosas 10. Subclinical interstitial lung disease: why you should care. Am J Respir Crit Care Med 2012;185:1147-53.

27 Putman RK, Rosas IO, Hunninghake GM. Genetics and early detection in idiopathic pulmonary fibrosis. Am J Respir Crit Care Med 2014;189:770-8.

28 Rosas IO, Dellaripa PF, Lederer DJ, et al. Interstitial lung disease: NHLBI workshop on the primary prevention of chronic lung diseases. Ann Am Thorac Soc 2014;11(Suppl 3):S169-77.

29 Raghu G, Weycker D, Edelsberg J, et al. Incidence and prevalence of idiopathic pulmonary fibrosis. Am J Respir Crit Care Med 2006;174:810-6.

30 Iwai K, Mori T, Yamada N, et al. Idiopathic pulmonary fibrosis. Epidemiologic approaches to occupational exposure. Am J Respir Crit Care Med 1994:150:670-5.

31 Fernández Pérez ER, Daniels CE, Schroeder DR, et al. Incidence, prevalence, and clinical course of idiopathic pulmonary fibrosis: a population-based study. Chest 2010;137:129-37.

32 Putman RK, Gudmundsson G, Araki T, et al. The MUC5B promoter polymorphism is associated with specific interstitial lung abnormality subtypes. Eur Respir J 2017;50:1700537.

33 Doyle TJ, Washko GR, Fernandez IE, et al. COPDGene Investigators. Interstitial lung abnormalities and reduced exercise capacity. Am J Respir Crit Care Med 2012;185:756-62.

34 Ash SY, Harmouche R, Putman RK, et al. Clinical and genetic associations of objectively identified interstitial changes in smokers. Chest 2017;152:780-91.

35 Axelsson GT, Putman RK, Miller ER, et al. Interstitial lung abnormalities and physical function. ERJ Open Res 2018:4:00057-2018

36 Miller ER, Putman RK, Vivero M, et al. Histopathology of interstitial lung abnormalities in the context of lung nodule resections. Am J Respir Crit Care Med 2018;197:955-8.

37 El-Chemaly S, Ziegler SG, Calado RT, et al. Natural history of pulmonary fibrosis in two subjects with the same telomerase mutation. Chest 2011;139:1203-9.

38 Ho JE, Gao W, Levy D, et al. Galectin-3 Is associated with restrictive lung disease and interstitial lung abnormalities. Am J Respir Crit Care Med 2016;194:77-83.

39 Armstrong HF, Podolanczuk AJ, Barr RG, et al. Serum Matrix Metalloproteinase-7, Respiratory Symptoms, and Mortality in Community-Dwelling Adults. MESA (MultiEthnic Study of Atherosclerosis). Am J Respir Crit Care Med 2017;196:1311-7.

40 Araki T, Putman RK, Hatabu H, et al. Development and progression of interstitial lung abnormalities in the framingham heart study. Am J Respir Crit Care Med 2016:194:1514-22.

41 Podolanczuk AJ, Oelsner EC, Barr RG, et al. High attenuation areas on chest CT and clinical respiratory outcomes in community-dwelling adults. Am J Respir Crit Care Med 2017. 


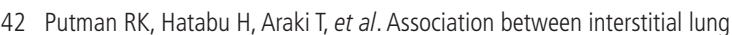
abnormalities and all-cause mortality. JAMA 2016;315:672-81.

43 Putman RK, Hunninghake GM, Dieffenbach PB, et al. Interstitial lung abnormalities are associated with acute respiratory distress syndrome. Am J Respir Crit Care Med 2017;195:138-41.

44 Pompe $\mathrm{E}$, de Jong PA, Lynch DA, et al. Computed tomographic findings in subjects who died from respiratory disease in the National Lung Screening Trial. Eur Respir J 2017:49:1601814.

45 Nishino M, Cardarella S, Dahlberg SE, et al. Interstitial lung abnormalities in treatment-naive advanced non-small-cell lung cancer patients are associated with shorter survival. Eur J Radiol 2015;84:998-1004.

46 Lynch DA, Sverzellati N, Travis WD, et al. Diagnostic criteria for idiopathic pulmonary fibrosis: a Fleischner Society White Paper. Lancet Respir Med 2018:6:138-53.

47 Hunninghake GW, Lynch DA, Galvin JR, et al. Radiologic findings are strongly associated with a pathologic diagnosis of usual interstitial pneumonia. Chest 2003; 124:1215-23.

48 Hansell DM, Bankier AA, MacMahon H, et al. Fleischner Society: glossary of terms for thoracic imaging. Radiology 2008;246:697-722.

49 Wells AU, Kokosi MA. Subclinical interstitial lung abnormalities: toward the early detection of idiopathic pulmonary fibrosis? Am J Respir Crit Care Med 2016;194:1445-6.

50 American Thoracic Society European Respiratory Society. American Thoracic Society/ European Respiratory Society International Multidisciplinary Consensus Classification of the Idiopathic Interstitial Pneumonias. This joint statement of the American Thoracic Society (ATS), and the European Respiratory Society (ERS) was adopted by the ATS board of directors, June 2001 and by the ERS Executive Committee, June 2001. Am J Respir Crit Care Med 2002;165:277-304.

51 Doyle TJ, Washko GR, Fernandez IE, et al. Interstitial lung abnormalities and reduced exercise capacity. Am J Respir Crit Care Med 2012;185:756-62.

52 Travis WD, Costabel U, Hansell DM, et al. An official American Thoracic Society/ European Respiratory Society statement: Update of the international multidisciplinary classification of the idiopathic interstitial pneumonias. Am J Respir Crit Care Med 2013; 188:733-48.

53 Raghu G, Remy-Jardin M, Myers JL, et al. Diagnosis of idiopathic pulmonary fibrosis. an official ATS/ERS/JRS/ALAT clinical practice guideline. Am J Respir Crit Care Med 2018;198:e44-e68.

54 Sodickson A, Baeyens PF, Andriole KP, et al. Recurrent CT, cumulative radiation exposure, and associated radiation-induced cancer risks from CT of adults. Radiology 2009;251:175-84

55 Noble PW, Albera C, Bradford WZ, et al. Pirfenidone for idiopathic pulmonary fibrosis: analysis of pooled data from three multinational phase 3 trials. Eur Respir $J$ 2016;47:243-53.

56 Ley B, Collard HR, King TE. Clinical course and prediction of survival in idiopathic pulmonary fibrosis. Am J Respir Crit Care Med 2011;183:431-40. 